\title{
Tasks Currently Faced by Yogo Teachers in Japan
}

\author{
Kazuko Iwasaki ${ }^{1,2, *} \&$ Toshiyuki Watanabe ${ }^{1,3}$ \\ ${ }^{1}$ Takasaki University of Health and Welfare, The Department of Health and Welfare Doctor's \\ Course, Takasaki, Japan \\ ${ }^{2}$ Maebashi Municipal Amagawa Elementary School, School Health Room, Maebashi, Japan \\ ${ }^{3}$ School of Health Science, Tokai University, Isehara, Japan \\ *Corresponding author: 37-1 Nakaorhuicho, Takasaki, Gunma 370-33, Japan. Tel: \\ 27-352-1290 E-mail: kazuko.himawari715@gmail.com
}

Received: January 28, 2017 Accepted: March 10, 2017 Published: March 18, 2017

doi:10.5296/ije.v9i1.10661 URL: https://doi.org/10.5296/ije.v9i1.10661

\begin{abstract}
The Yogo Teacher in Japan is equivalent to the role of school nurse in the US. The purpose of the research is to clarify the duties facing school nurse teachers working in elementary schools in Japan, the knowledge and skills required for coping with them, and their training needs. We surveyed 536 nursing teachers nationwide. 1) Job difficulties confronted by Yogo Teachers include collaboration (19.2\%), which includes collaboration at the school and with family members. 2) The knowledge and skills necessary for Yogo Teachers included Self-Education Ability (24.3\%), and mainly required communication skills and coordination ability. 3) In training needs, Psychology and Psychiatry (22.0\%) were uppermost, and improvement of counseling skills and ability was required. It is important to build a system that enables Yogo Teachers to educate themselves in collaboration techniques and theories, and to practice supervision by mental health specialists.
\end{abstract}

Keywords: Yogo Teacher(school nurse), Job difficulties, Knowledge and Skills, Training needs, collaboration, Mental health specialist 


\section{Ml Macrothink}

\section{Introduction}

The Yogo Teacher in Japan is equivalent to the role of school nurse in the US. However, in Japan, a Yogo Teacher is positioned not as a nurse but as a teacher, and oversees health care and health education.

Yogo Teachers, through their continued efforts, have produced marked improvement in their physical work during the 70 years since World War II. The main job of a Yogo Teacher is to improve nutrition management, provide infection control, treatment of abrasions, lifestyle improvement, and respond to physical problems. Students' mental health problems, such as school refusal and bullying, began to increase in schools from the 1980s. In 1994, there was a case of child suicide by bullying that was reported by the mass media as a major social problem and citizen's attention turned to students' mental health. The Ministry of Education, Culture, Sports, Science and Technology prize launched school counselors in 1995 and began to care for children's mental health. However, school counselors are not located in all elementary schools, and even if there is a school counselor, they only visit once a week.

Miki (2013) and Iwasaki and Watanabe (2016) pointed out that several tasks are hidden beneath the surface injuries and illnesses of children coming to the school health room. A Yogo Teacher, who is in the school health room every day, can detect children's mental health signs and respond immediately.

It is no exaggeration to say that the problems experienced by Yogo Teachers in Japan are the same as those of children in Japan. The purpose of this research is to clarify the difficulties experienced by elementary school Yogo Teachers, the knowledge and skills necessary for coping with them, and their training needs.

\section{Method}

\subsection{Subjects}

The subjects of the survey were Yogo Teachers working at 2000 elementary schools according to a nationwide school overview. We extracted schools by random sampling (systematic extraction) so as not to be biased toward a specific area.

\subsection{Investigation Period}

The study was conducted during February 2016.

\subsection{Survey Method}

We conducted a questionnaire survey on Yogo Teachers who work for the target elementary schools. In the investigation, Yogo Teachers of the target schools were mailed a request letter clearly stating the purpose of the research and a return envelope. Because letters were returned by 20 schools due to reasons of school closure, 1,980 schools were targeted. Responses were obtained from 540 cases; the collection rate was $27.3 \%$, and the effective response rate was 536 cases. 
Questionnaire items included basic information such as years of experience working at the current school, years of experience as a Yogo Teacher, basic information such as sex, age, department of origin, and three specific questions: (1) What are your job difficulties, (2) What knowledge and skills do you have? (3) What are your training needs? The reason for including the free description questions was to eliminate researcher subjectivity from the research. This is because using standard questionnaires alone is insufficient to gather the true opinions of Yogo Teachers.

\subsection{Analysis Method}

Regarding "job difficulties," since it is an abstract phrase, we used the grounded theory approach (GTA) to analyze the responses. In data classification, to eliminate the researcher's subjectivity bias, we followed the GTA-based procedure of sectioning, property, and dimension creation. We labeled similar contents with label names, and further grouped the labels into "category names."

Regarding the remaining two questions, "knowledge and skills" and "training needs," as there were many specific words (e.g., "counseling," "emergency treatment skills"), we did not segment the description contents. Content analysis summarized by similarity was used.

The researchers attached labels that reflected the contents faithfully and made them into categories by collecting them, for example, First Aid, First Aid Skills, Crisis management ability, Emergency judgment, Ability to distinguish severity, Knowledge and technology for life support, Appropriate treatment at emergency, and Crisis response capability were categorized as "Emergency response." The classification and naming of labels and categories were done by two researchers to increase study reliability.

This research was approved by the Takasaki University of Health and Welfare Ethics Review Committee (Units No. 2372). Yogo Teachers who sent reply mails were considered to have consented to participate.

\section{Results}

\subsection{Basic Data of Respondents (Table 1)}

Attributes of the respondents (536 people) are shown in Table 1. The age group with the highest proportion was in the 50s with $165(30.9 \%)$, followed by $137(25.6 \%)$ in the 40s. The percentage of those aged 40 years or over accounted for $56.5 \%$, and there were $125(23.2 \%)$ in the $20 \mathrm{~s}$.

There were $96(17.9 \%)$ Yogo Teachers with less than five years of experience, $80(14.9 \%)$ with 5 to 9 years, 72 people $(13.4 \%)$ with 10 years to 19 years, 121 people $(22.6 \%)$ with 20 years to 29 years, and $167(31.2 \%)$ with over 30 years.

The majority of Yogo Teachers had qualifications in education, with 301 (56.2\%), followed by 103 nursing staff $(19.2 \%)$. 


\section{Ml Macrothink}

Table 1. Characteristics of Subjects

\begin{tabular}{lr}
\hline$(\mathrm{n}=536)$ & $\mathrm{N}(\%)$ \\
\hline Age (years old) & $125(23.2)$ \\
$20-29$ & $109(20.3)$ \\
$30-39$ & $137(25.6)$ \\
$40-49$ & $165(30.9)$ \\
over 50s & \\
\hline Years of experience (years) & $96(17.9)$ \\
Under 5 & $80(14.9)$ \\
$5-9$ & $72(13.4)$ \\
10-19 & $121(22.6)$ \\
$20-29$ & $167(31.2)$ \\
Over 30 & \\
\hline Department and School & $301(56.2)$ \\
Education & $103(19.2)$ \\
Nursing & $38(7.1)$ \\
Vocational school & $24(4.5)$ \\
Housekeeping Nutrition & $13(2.4)$ \\
Medicine & $12(2.2)$ \\
Welfare & $9(1.7)$ \\
Training center & $4(0.7)$ \\
Physical education & $3(0.6)$ \\
Psychology & $3(0.6)$ \\
Health & $26(4.9)$ \\
Other &
\end{tabular}

\subsection{Job Difficulties (Table 2)}

The researchers summarized the descriptive contents into 53 labels and 11 categories. The categories in descending order of number of responses were described as follows: (1) Collaboration [7 labels, 193 answers (19.2\%)], (2) Mental health knowledge and correspondence [6 labels, 160 answers (15.9\%)], (3) Proper placement of Yogo Teacher in school [8 labels, 154 answers (15.3\%)], (4) Work diversification [8 labels, 151 answers (15.0\%)], (5) Medical knowledge and correspondence [9 labels, 127 answers (12.6\%)], (6) Problems related to classes [4 labels, 94 answers (9.3\%)], (7) Problems of the higher system [5 labels, 46 answers (4.6\%)], (8) Transforming family [2 labels, 44 answers (4.4\%)], (9) Personal problems [1 label, 23 answers $(2.3 \%)],(10)$ Problems on the school side [2 labels, 9 answers $(0.2 \%)],(11)$ Others [12 responses $(1.2 \%)]$. 
Table 2. Job Difficulties

\begin{tabular}{|c|c|}
\hline $\begin{array}{l}\text { (1) Collaboration } \\
193 \text { answers }(19.2 \%)\end{array}$ & $\begin{array}{l}\text { Collaboration within school (68) } \\
\text { Collaboration with family members (61) } \\
\text { Collaboration with class teachers (24) } \\
\text { Collaboration (13) } \\
\text { Cooperation with other Yogo Teachers (11) } \\
\text { Cooperation with external organizations (10) } \\
\text { Collaboration with school physicians (6) }\end{array}$ \\
\hline $\begin{array}{l}\text { (2) Mental health knowledge } \\
\text { and correspondence } \\
160 \text { answers }(15.9 \%)\end{array}$ & $\begin{array}{l}\text { Understanding and supporting children's minds (82) } \\
\text { School refusal (21) } \\
\text { Attendance to school health room (17) } \\
\text { Health consultation activities (15) } \\
\text { Developmental disorders (15) } \\
\text { Special support children (10) }\end{array}$ \\
\hline $\begin{array}{l}\text { (3) Proper placement of Yogo } \\
\text { Teacher in School } \\
154 \text { answers }(15.3 \%)\end{array}$ & $\begin{array}{l}\text { Busy (54) } \\
\text { One person workplace problem (39) } \\
\text { Small school (22) } \\
\text { Large school (18) } \\
\text { Lack of consultation partner (10) } \\
\text { Yogo Teacher's placement criteria issue (6) } \\
\text { Yogo Teacher's status treatment (3) } \\
\text { Differences between school characteristics and Yogo } \\
\text { Teacher's role (2) }\end{array}$ \\
\hline $\begin{array}{l}\text { (4) Work Diversification } \\
151 \text { answers }(15.0 \%)\end{array}$ & $\begin{array}{l}\text { Duties are diversified (47) } \\
\text { Time management (22) } \\
\text { Management of public health room (26) } \\
\text { Work outside the duties (15) } \\
\text { Utilization of IT (12) } \\
\text { Management of School Health Committee (12) } \\
\text { Office processing (11) } \\
\text { Yogo Teacher 's response to absence (6) }\end{array}$ \\
\hline $\begin{array}{l}\text { (5) Medical knowledge and } \\
\text { correspondence } \\
127 \text { answers }(12.6 \%)\end{array}$ & $\begin{array}{l}\text { Emergency response (69) } \\
\text { Judgment of consultation of medical institution (20) } \\
\text { Physical correspondence (12) } \\
\text { Physical Assessment (7) } \\
\text { Response to medical examination (6) } \\
\text { Medical knowledge (4) } \\
\text { Children who have allergies (3) } \\
\text { Measures against food allergies (3) } \\
\text { Medical correspondence (3) }\end{array}$ \\
\hline
\end{tabular}


(6) Problems related to classes Teaching and education (53)

94 answers $(9.3 \%) \quad$ Health guidance (26)

A sense of difficulty about health education (11)

Research and in-school training (4)

(7) Problems of the higher system

46 answers $(4.6 \%)$
Problems when changing work place (13)

Municipal issues (12)

History of change (9)

Differences in educational awareness of teachers (8)

Differences in Yogo Teacher's status (4)
(8) Transforming family 44 answers $(4.4 \%)$

\begin{tabular}{ll}
\hline $\begin{array}{l}\text { (9) Personal problems } \\
23 \text { answers }(2.3 \%)\end{array}$ & Own problems (23) \\
\hline $\begin{array}{l}\text { (10) Problems on the school } \\
\text { side }\end{array}$ & Management issue (7) \\
9 answers $(0.2 \%)$ & School administration (2) \\
\hline $\begin{array}{l}\text { (11) Others } \\
12 \text { answers }(1.2 \%)\end{array}$ & Others (12) \\
\hline
\end{tabular}

\subsection{Required Knowledge and Skills (Table 3)}

The researchers summarized the descriptions in 119 labels and 15 categories. The most common categories were as follows: (1) Self-education Ability [30 labels, 417 answers (24.3\%)], then (2) Emergency response [8 labels, 336 answers (19.6\%)], (3) Skills of Mental care [9 labels, 245 answers (14.3\%)], (4) Knowledge of the body [15 labels, 203 answers (11.8\%)], (5) Health guidance and health education [11 labels, 100 answers (5.8\%)], (6) Understanding of children's minds [12 labels, 86 answers (5.0\%)], (7) Development and developmental disorders [3 labels, 75 answers (4.4\%)], (8) Knowledge of prevention [5 labels, 60 answers (3.5\%)], (9) Collaboration with external agencies [5 labels, 56 answers (3.3\%)], (10) IT and administrative processing [5 labels, 51 answers (3.0\%)], (11) Collaboration in the school [5 labels, 25 answers (1.5\%)], (12) Collaboration with family [2 labels, 20 answers (1.2\%)], (13) Collaborative force [2 labels, 18 answers (1.0\%)], (14) Health care [3 labels, 16 answers $(0.9 \%)$, (15) Job performance we classified as ability improvement [4 labels, 10 answers $(0.6 \%)]$. 


\section{Macrothink}

Table 3. Required Knowledge and Skills

\begin{tabular}{|c|c|}
\hline $\begin{array}{l}\text { (1) Self-education Ability } \\
417 \text { answers }(24.3 \%)\end{array}$ & $\begin{array}{l}\text { Communication skill (105) } \\
\text { Coordinating ability (61) } \\
\text { Management ability (29) } \\
\text { Planning skill (28) } \\
\text { Presentation skills (22) } \\
\text { Judgment ability (22) } \\
\text { Adjustment ability (21) } \\
\text { Responsive change (13) } \\
\text { Practical ability (9) } \\
\text { school health room attendance (9) } \\
\text { Experience (6) } \\
\text { Ability to perform (6) } \\
\text { Ability to transmit (5) } \\
\text { Response ability (5) } \\
\text { Human nature as a Yogo Teacher (5) } \\
\text { Transmission ability (5) } \\
\text { Management of own health (5) } \\
\text { Ability to lead (5) } \\
\text { Ability to promote (4) } \\
\text { Imagination (4) } \\
\text { Observability (4) } \\
\text { How to earn trust (4) } \\
\text { Extensive expertise (4) } \\
\text { Method with core role (4) } \\
\text { Strength of the heart (4) } \\
\text { Knowledge of obstacles and ability to distinguish (3) } \\
\text { Operating power (3) } \\
\text { Broad knowledge (3) } \\
\text { Ability to respond by one person (2) } \\
\text { Others (17) }\end{array}$ \\
\hline $\begin{array}{l}\text { (2) Emergency response } \\
336 \text { answers }(19.6 \%)\end{array}$ & $\begin{array}{l}\text { First aid skills (173) } \\
\text { First Aid First Aid Skill (113) } \\
\text { Crisis management ability (23) } \\
\text { Emergency judgment (15) } \\
\text { Ability to distinguish severity (3) } \\
\text { Knowledge and technology for life support (3) } \\
\text { Appropriate treatment at emergency (3) } \\
\text { Crisis response capability (3) }\end{array}$ \\
\hline
\end{tabular}


(3) Skills of Mental care 245 answers (14.3\%)
Counseling ability (179)

Health consultation activities (31)

Listening skills (8)

Power to see and observe mind and body (8)

Social skill training (4)

Entertainment power (3)

Therapy skill (3)

Coaching (2)

Others (7)

(4) Knowledge of the body

Medical knowledge and skills (58)

203 answers (11.8\%)

Knowledge related to nursing (18)

Knowledge and correspondence of allergies (17)

Child care diagnosis (16)

Response to diseases (10)

Correspondence to injuries (9)

Information on medical institutions (7)

Mechanism of the body (7)

Knowledge of various diseases (5)

Knowledge on health (4)

Knowledge of health science (3)

Knowledge of nutrition (3)

Assessment of examination of medical institution (2)

Others (4)

(5) Health guidance and health education 100 answers $(5.8 \%)$
Attractive class practice and health guidance (38)

Health guidance (19)

Health education (14)

Health learning (5)

Combined promotion of health management and health education/health guidance (4)

General knowledge of education (4)

Media (4)

Health education (3)

Sex education skills (2)

Safety management (2)

Others (5)
(6) Understanding of children's minds 86 answers $(5.0 \%)$
Understanding and support for children (21)

Knowledge and skills on health (18)

Psychological care (9)

Mental health knowledge and skills (7)

Assessment ability about mind and body (6)

About mental health (5) 
Knowledge and technology capable of individual response (5)

Ability to see children (5)

Ability to respond to school refusal (3)

Ability to respond to school attendance (2)

To be fond of children (2)

Others (3)

(7) Development and

Knowledge and correspondence of special support (32)

developmental disability

75 answers (4.4\%)

Knowledge of developmental disorders and correspondence

(32)

Knowledge on developmental psychology (11)

(8) Knowledge of prevention 60 answers $(3.5 \%)$

Prevention of infectious diseases (25)

Diseases common to children (24)

Knowledge and technology for injury prevention (7)

Preventive medicine (2)

Others (2)

\begin{tabular}{cl}
\hline $\begin{array}{c}\text { (9) Collaboration with } \\
\text { external }\end{array}$ & Training to acquire new information (26) \\
56 answers (3.3\%) & Collaboration with external specialized agencies (21) \\
& Collaboration with multi-occupation (5) \\
& Collaboration with specialized agencies (2) \\
& Information on specialty agencies of foreign affairs (2) \\
\hline (10) IT and administrative & How to use information equipment (29) \\
processing & Data management and analysis (7) \\
51 answers (3.0\%) & Information gathering and processing (6) \\
& Clerical processing capacity (5) \\
& How to make and use materials (4) \\
\hline (11) Collaboration in the & Collaboration with officials and school organization (17) \\
school & Organization management (2) \\
25 answers (1.5\%) & School health committee (2) \\
& Collaboration with teacher's teacher (2) \\
& Ability to connect child and parents with teachers (2) \\
\hline (12) Collaboration with & Collaboration with parents (16) \\
family & Response to parents (4) \\
20 answers (1.2\%) & \\
\hline (13) Collaboration force & Cooperative ability (15) \\
18 answers (1.0\%) & Power to connect to various people (3) \\
\hline (14) Health care & Knowledge of health management (6) \\
16 answers (0.9\%) & Health checkup (6) \\
& Environmental hygiene (4) \\
improvement & Welfare and social system (4) \\
10 answers (0.6\%) & Increase child self-affirmation (2) \\
\hline & Onderstanding and legal grounds for children's rights (2) \\
\hline (15) Job performance we & \\
\hline & \\
\hline &
\end{tabular}




\section{MInstitute ${ }^{\text {Macrothink }}$}

\subsection{Training Needs (Table 4)}

Descriptive answers were classified into 107 labels and 15 categories. Categories were derived from similarities in the semantic contents. The categories with the highest numbers of labels were as follows: (1) Psychology and Psychiatry [15 labels, 236 answers (22.0\%)], (2) First-aid measures [10 labels, 182 answers (16.9\%)], (3) Special support [13 labels, 138 answers (12.8\%)], (4) Knowledge of the body [12 labels, 128 answers (11.9\%)], (5) Self-education Ability [17 labels, 116 answers (10.8\%)], (6) Health guidance and health education [11 labels, 103 answers $(9.6 \%)$ ], (7) Improve administrative processing capacity [3 labels, 44 answers (4.1\%)], (8) Cooperation in the region [3 labels, 31 answers (2.9\%)], (9) Health care [2 labels, 20 answers (1.9\%)], (10) Children - How to engage with [7 labels, 20 answers (1.9\%)], (11) Family understanding and correspondence [3 labels, 18 answers (1.7\%)], (12) School health room management [2 labels, 12 answers (1.1\%)], (13) Collaboration with other external jobs [3 labels, 12 answers (1.1\%)], (14) Collaboration within the school [3 labels, 9 answers $(0.8 \%)$ ], (15) Collaboration with external specialized agencies [3 labels, 6 answers $(0.6 \%)]$.

Table 4. Training Needs

\begin{tabular}{ll}
\hline (1) Psychology and & Improve counseling ability (117) \\
Psychiatry & Case study meeting (25) \\
236 answers (22.0\%) & Health consultation activities (24) \\
& Mental health (14) \\
& Education of mental health/mind (11) \\
& Mental care (11) \\
& Psychology (9) \\
& Child psychology (6) \\
& Knowledge of mental illness (3) \\
& Faculty staff mental health (3) \\
& Understanding of children (3) \\
& Mental and physical development and health (3) \\
& Listening method (2) \\
& Psychological test (2) \\
& Others (3) \\
Emergency treatment (97) & First Aid (37) \\
Injury knowledge and correspondence (15) \\
Emergency system and judgment (9) \\
Crisis management (8) \\
Physical treatment (4) \\
Judgment of necessity of medical examination to medical \\
institution (4) \\
Judgment in case of emergency (3) \\
Near hat (3) \\
Others (2) \\
\hline
\end{tabular}


(3) Special support 138 answers $(12.8 \%)$
Knowledge and understanding of special support (35)

Knowledge of developmental disorders and how to respond (33)

School refusal (13)

How to engage children with developmental disabilities (9)

School attendance school (9)

Abuse (8)

Responding to children who need special assistance (7)

How to identify the necessity of special support (5)

LGBT (5)

Universal design (2)

Suicide prevention (2)

Self-injury (2)

Others (8)
(4) Knowledge of the body 128 answers $(11.9 \%)$

Physical assessment (27)

The latest medical and medical information (25)

Allergy knowledge and correspondence and management (23)

Responding to sickness knowledge (15)

Assessment (9)

Knowledge and understanding on representative diseases (5)

Preventive medicine (4)

Nursing (3)

Growth curve (3)

Prevention of infectious diseases (3)

Brain science (3)

Others (8)

(5) Self-education Ability

Latest training on duties (21)

116 answers $(10.8 \%)$
Training of new knowledge and information (11)

Improve communication skills (9)

Management of anger (9)

Knowledge necessary for role of coordinator (8)

Knowledge of coaching (8)

About management (5)

Social skill training (4)

Laws and applications involving nurse teachers (4)

Methodology. Presentation. How to study (3)

Management ability (2)

Life skills (2)

Assertion training (2)

RIFCR (2)

About chemicals (2)

Stress management (2)

Others (22) 
(6) Health guidance and health education 103 answers $(9.6 \%)$
Effective health learning and health guidance methods (55)

Sex education (14)

Lifestyle training (6)

Knowledge and prevention of health damage of media (6)

On the practice of health education (5)

SST (4)

Teaching obesity (4)

Health education (3)

Boards where children are interested (2)

AIDS knowledge and education (2)

Others (2)

(7) Improve administrative processing capacity 44 answers $(4.1 \%)$

IT Utilization Technology (34)

Improvement in office work efficiency (7)

Data analysis (3)

(8) Cooperation in the region Exchange information with Yogo teacher of other schools (18)

31 answers $(2.9 \%)$

How to approach organizational activities (12)

Others (1)

(9) Health care

New examinations such as examination of exercisers (19)

20 answers $(1.9 \%)$

Others (1)

(10) Children-How to engage with

Response to children (5)

Correspondence with children (4)

20 answers $(1.9 \%)$

How to engage individual support (3)
Understanding of contemporary children from sociological point of view (2)

Relationship with children with mental problems (2)

Exercise to raise children's self-affirmation (2)

Others (2)

(11) Family understanding and correspondence 18 answers (1.7\%)

Cooperation with family members and correspondence (14)

Family Assessment (2)

Child-rearing support (2)

(12) School health room management

Management of nurse's office (10)

Response in the public health room (2)

12 answers $(1.1 \%)$

(13) Collaboration with other external jobs 12 answers (1.1\%)

Collaboration with external specialized agencies (9)

Know the work of social workers (2)

Others (1)

(14) Collaboration within the school

Ability to promote common understanding among staff (4)

9 answers $(0.8 \%)$

How to support team (4)

(15) Collaboration with Others (1)

external specialized agencies

Collaboration with facilities related to medical institutions (3)

6 answers $(0.6 \%)$
I would like to hear stories of good cooperation experiences

with medical institutions (2)

Others (1) 


\section{Discussion}

In Japan, the occupation that conducts health management of students is called a Yogo Teacher, which, unlike a school nurse in the US, is a school board member in each district. A Yogo Teacher in Japan is a full-time faculty member of each school, and the supervisor of the Yogo Teacher is the principal.

Regarding educational background, about half of participants had studied education, and about $20 \%$ had studied nursing, which is different from the United States. A Yogo teacher has a wide range of duties and is responsible for health care, health education, health consultation activities, and so on. They are located in primary schools, middle schools, high schools, special support schools (some kindergartens), and elementary schools, and are responsible for identifying and responding to all the physical and psychological health needs of the students.

As a Yogo teacher, I have observed that the health problems faced in the past 10 years have become diverse and complicated, and I felt that the difficulty of dealing with these problems has increased. The researchers planned this research to clarify the job difficulties faced by Yogo Teachers in Japan, the knowledge and skills required to respond to them, and the training necessary for their work.

Sakou et al. (2008) used the KJ method to examine descriptions of the job difficulties and training needs identified by 14 Yogo Teachers in a certain area. Based on their results, Yogo Teachers felt the three job difficulties were "Correlation/Collaboration," "contents of Job," and "job scope is unclear." In the question about training needs, there were many requests for "network making" and "Professional knowledge and skills." They reported Yogo Teachers requested a close network for training and obtaining new knowledge and skills.

Ishida and Sonoda (2016) asked approximately 500 Yogo Teachers in A prefecture about the relationship between their self-education ability and job difficulties. Yogo Teachers' job difficulties were found to consist of four factors: "correspondence of students/guardians," "public relations activities," "collaboration for environmental sanitation activities," and "office work."

Two previous studies showed increasingly diverse health problems and job difficulties. These studies restricted the area of investigation and targeted a small sample. The role of the Yogo Teacher varies in different prefectures because the boards of education and the educational systems are different (Tsukahara, Kasamaki, Matsui, \& Hata, 2016), and therefore a nationwide investigation is necessary.

The recovery rate of the survey was about $30 \%$, but more than $50 \%$ of the respondents are experienced Yogo Teachers in their 40s and 50s. Therefore, we consider the findings worthy of further consideration.

"Job difficulties in collaboration" was the most frequent category at 19.2\%, while "job difficulties in mental knowledge and correspondence" was $15.9 \%$.

Looking at the breakdown of collaboration, it became clear that there are many job difficulties relating to collaboration within elementary schools and cooperation with family. 
Collaboration is necessary for children with mental health problems, which are increasingly common in Japan. Many Yogo Teachers feel that collaboration is not functioning smoothly, and there are many others who have difficulties with collaboration with families.

In Japan, there is a word meaning "attendance to school health room." Attendance to school health room is defined as "always staying in the school health room or students who are almost always in the school health room while in school, even if they can attend a specific lesson." In a 1996 report (Japanese Society of School Health, 2012), the proportion of students in "Attendance to school health room" rose to $12.1 \%$ of the total and in a 2011 survey (Japanese Society of School Health, 2012) it rose to $28.5 \%$ of the total. Regarding school attendance, family problems occur in the background of the health room as children are treated. The background of school health room attendance often involves family problems such as poverty, maternal family, domestic violence, etc. Children experience the Yogo Teacher as a surrogate parent and the school health room as a second home. Students feel that the health room is a place where they can relax among people who are like a family and feel relieved; it is regarded as a space that nourishes mental and bodily growth (Sakai, Okada, \& Tukagoshi, 2005).

In Japan, case reports of school health room attendance point out the importance of collaboration (Yasufuku, Nakasumi, \& Tanaka, 2009; Okawa, Notani, Kagioka, Sato, \& Yamamoto, 2004). Hanazawa (2009) stated that school health room attendance has important meanings in the process of recovery from psychiatric diseases of puberty. In the process of transitioning from mother-child relations to social relationships, school nurse teachers reported the value of nurse teachers as providing a mother's role in school, as well as a social aspect of a teacher belonging to the school. The teacher plays an important role of bridging between family and society.

Kitamura and Katou (2007) stated that it is important for student understanding to consider the family composition and domestic circumstances from the standpoint of school education, but it is difficult for school nurse teachers to understand the students' families at present.

Collaborative care that works with family members and external organizations is important for Yogo Teachers, but in Japan's current situation, this does not function smoothly and Yogo Teachers experience job difficulties.

School nurses in the United States can respond in school while viewing medical records such as the degree of disease and the contents of medication, if parental permission is obtained. However, by law, school nurse teachers in Japan cannot see student medical information or charts. This represents an important difference from American school nurses.

The Central Council Education (2008) report in 2008 showed that "the Yogo teacher plays a central role in promoting school health activities and the Yogo teacher plays a role as a coordinator." However, the specific contents of "who," "where," and "how" were not indicated in it. Hence, many school nurse teachers do not know the concrete methods and theory of collaboration and find collaboration difficult.

The Self-Education Ability [30 labels, 417 responses (24.3\%)] that showed the highest value 
in required knowledge and skills was the emergency response [8 labels, 336 answers (19.6\%)]; the third was skills of Mental care [9 labels, 245 answers (14.3\%)]. Most labels in Self-Education Ability relate to communication skills (105) and coordination ability (61), which is related to the number of Yogo Teachers with job difficulties in collaboration.

Goto and Shiraishi (2011) said that it is important to nurture qualities and abilities as a coordinator of a Yogo Teacher, or to train them. Focusing on postgraduate education and postgraduate training aims to improve one's qualities as a coordinator. Collaboration theory and technique can provide the foundation for the role of a coordinator, but concrete training and supervision are not done in Japan.

The role expected of a Yogo Teacher in children's health management in Japan is increasing, but on the other hand, the problem of proper placement is increasingly becoming an issue. A Yogo Teacher often works alone in the school health room. There is only one Yogo Teacher in the school and they therefore cannot consult with others of the same occupation, while general teachers are in daily contact with faculty of the same profession.

Takeda, Asakura, and Okada (2010) clarified that the Yogo Teacher is a very different job class from general teachers. Takeda et al. reported that relationships with general faculty are stressful and influence Yogo Teacher's satisfaction with their work in regard to human relations within elementary schools. Takeda et al.'s report agreed with the finding that Yogo Teachers have many difficulties in collaboration within elementary schools.

In the United States, there is a clear definition of the role of school nurse. Their role often overlaps with the role played by Japan's Yogo teacher. Rather, a Yogo Teacher is able to find children's problems early in that they work for the school. It is necessary to promote collaboration, which is as important in the role of school nurse in the US as it is to Yogo Teachers in Japan. Yogo Teachers in Japan often talk about "counseling" words such as techniques of listening/accepting/responding when dealing with injuries (Sawamura et al., 2013).

Kono et al. (2013) stated that appropriate injury treatment is the most reliable way to build relationships between children and a Yogo Teacher. Emergency treatment is an important element of health consultation activities and cannot be separated.

According to the results, the needs for mental care skills were high, among which the counseling ability (179) was high. In 1994 in Japan, the incidence of child bullying became a major social problem. In 1997, "health counseling function" was added to Yogo Teachers' new role in the Health and Physical Education Council. This role is different from counseling by general teachers and school counselors. It should be emphasized that counseling should be done fully utilizing the job characteristics of a Yogo Teacher and the function of school health room in Japan under the name "Health Consultation Activity" has been established (Iwasaki $\&$ Watanabe, 2016).

Yogo Teachers have an opportunity to become involved in collecting information by cherishing their daily relationships with children. The Yogo Teacher in Japan is a member of the school health room, so they can grasp the state and mental condition of the children. 


\section{Mll Macrothink}

International Journal of Education

ISSN 1948-5476

2017, Vol. 9, No. 1

On this point as well, Yogo Teachers understand that counseling ability ranks at the top of the knowledge and skills that are regarded as necessary.

Students attending the school health room often admit symptoms of somatization. These are caused by expressing psychological problems as physical symptoms. Training that increases the observation and counseling ability of Yogo Teachers for students is therefore needed. Yogo Teachers who studied psychology and psychiatry $(22.0 \%)$ were the ones who endorsed training needs. Among the training needs that were frequently mentioned was improvement of counseling skills (117). The second was emergency response (16.9\%).

Regarding job difficulties, collaboration with families was mentioned. Training to improve counseling skills and abilities by learning about collaborative care from the viewpoint of family is necessary. The author is currently conducting joint research on the significance and effectiveness of supervision for psychiatrists and family therapists.

In elementary schools in Japan, health observations are being conducted in school health rooms and classes. Health observation at a primary school in Japan means observing the health condition of children daily, to detect physical and mental health problems at an early stage and to respond appropriately (Ministry of Education, Culture, Sports, Science and Technology, 2010).

Performing health observation through morning health observation conducted by the class homeroom teacher and performing health checks throughout the school life is important not only for poor physical conditions but also for children's mental health concerns such as psychological stress and suffering, bullying, school refusal, abuse, and mental illness. The importance of health observation is increasing as it leads to early detection and early response to problems.

It is important to share information about "the state of children different from usual" with other staff and collaborate. Difficulties with collaboration create serious problems in collaboration within elementary school, but even in the responses to "Yogo Teacher's necessary knowledge and skills" and "Training needs," there was very little description about collaboration in elementary school. This is a very interesting result.

Even from my experiences as a researcher, Yogo Teachers do not recognize that "collaboration" should be learned. Collaboration has its opponents and Yogo Teachers are aware that it is not possible to receive training. Collaboration is not recognized in the educational setting in Japan as a technique or theory.

Kamata (2010) stated that Yogo Teachers need research and practical training that can leverage various system construction techniques such as collaboration, network formation, and so on. Okada (2010) also has a collaboration perspective. Okada also pointed out that academic construction for practice is under development.

To protect the health of elementary school students in Japan Yogo Teachers need to learn the technique and theory of collaboration and build a training system for practice. 


\section{Conclusion}

This study investigated 536 people to clarify the job difficulties faced by Yogo Teachers working in elementary schools in Japan, and the knowledge and skills needed for coping with them, and their training needs. Thus, the following knowledge was obtained.

1) Job difficulties confronted by Yogo Teachers include collaborations (19.2\%), which means collaboration at the school and collaboration with family members.

2) The knowledge and skills necessary for Yogo Teacher included Self-Education Ability $(24.3 \%)$, and mainly required communication skills and coordination ability.

3) In training needs, Psychology and Psychiatry (22.0\%) were uppermost, and improvement of counseling skills and ability was required.

4) Collaboration in job difficulties showed that high levels $(19.2 \%)$ of collaboration in elementary school were needed, but responses mentioning this were low at $1.5 \%$ in the knowledge and skills necessary for a Yogo Teacher and $0.8 \%$ in Training needs.

In addition to networking among school nurse teachers, it is important to hold case studies in order to consider psychiatrists, family therapists, certified psychologists, etc., and to advance research based on practice.

It is important to build a system that enables Yogo Teachers to demonstrate collaboration skills, to educate them in collaboration techniques and theories, and to practice supervision by mental health specialists such as psychiatrists, family therapists, and clinical psychologists.

\section{References}

Central Council Education. (2008). Retrieved March 14, 2017 from http://www.mext.go.jp/b_menu/shingi/chukyo/chukyo0/toushin/_icsFiles/afieldfile/200 9/01/14/001_4.pdf

Goto, H., \& Shiraishi, T. (2011). What is future of Yogo training at a time of change? Japanese Journal of School Health, 53, 197-199.

Hanazawa, H. (2009). Hokenshitu-toukou in the recovery process of anorexia nervosa. Bulletin of the Faculty of Education, Chiba University, 57, 53-56.

Ishida, Y., \& Sonoda, N. (2016). Relationship between self-education ability in solitary school nurse arrangements and job difficulties. Japanese Journal of Applied Psychology, $42(1), 12-19$.

Iwasaki, K., \& Watanabe, T. (2016). Recent research trends in-service training of Yogo teachers. Journal of Japanese Association of Health Consultation Activity, 11(1), 16-31.

Japanese Society of School Health. (2012). Investigation result of year 2011. The School Health Room usage investigation booklet. 
Kamata, H. (2010). Graduate school study program on the "Yogo" teachers ability and special quality of career and research work in pursuit of professional practice. Japanese Journal of School Health, 51, 390-394.

Kitamura, A., \& Katou, A. (2007). An investigation about progress of school inattendance and dropout in senior high schools. Nara University of Education Academic Repository, $56(2), 21-28$.

Kono, C., Watanabe, Y., Komatu, K., Takahashi, H., Isgihara, A., Furukawa, A., \& Osima, H. (2013). School nurses empowered by case studies: In the case of "common" treatment of students in the school nurse's room. Studies in School Health Counseling, 10(1), 57-65.

Miki, T. (2013) Health consultation and health consultation activities based on the law, concepts, and practice. Japanese Journal of School Health, 54, 481-486.

Okada, K. (2010). Qualitative research on academic construction of "Yogo" teacher and its challenges. Japanese Journal of School Health, 51, 366-370.

Okawa, M., Notani, M., Kagioka, M., Sato, H., \& Yamamoto, E. (2004). Development of the support system for the student - For the Yogo teacher who can support the children's mind. Kansai Women's College, 14, 39-52.

Sakai, K., Okada, K., \& Tukagoshi, M. (2005). The deeper meaning process of the health room for 'frequent visitors' at the junior high school, and influential factors. Analysis with the use of modified grounded theory approach. Japanese Journal of School Health, $47,321-333$.

Sakou, K., Izu, A., Tamura, K., Ichkawa, M., Uehara, Y., Fukusima, K., \& Nakashita, T. (2008). Difficulties and training needs encountered by Yogo teachers in daily practice. Journal of Japanese Association of Yogo Teacher Education, 11(1), 26-32.

Sawamura, F., Miki, T., Onuma, K., Kagawa, M., Rikimaru, M., Iwasaki, K., ... Asikawa, M. (2013). Investigation on actual conditions of touching technique and perceived effects by Yogo teachers - results from the questionnaire survey. Japanese Journal of School Health, 55, 3-12.

Takeda, F., Asakura, T., \& Okada, K. (2010). Factors related to the job satisfaction of Yogo teachers: An investigation of occupational stressors, social support, and self-esteem. The Japanese Society of Health and Human Ecology, 76(6), 253-263. https://doi.org/10.3861/jshhe.76.253

Tsukahara, K., Kasamaki, J., Matsui, K., \& Hata, G. (2016). The caliber and capability required for Yogo Teachers as well training course needs. Journal of Japanese Association of Yogo Teacher Education, 19(2), 41-48.

Yasufuku, J., Nakasumi, M., Tanaka, M., \& Asano, T. (2009). Non-attendance and support of the school nurse in health room. Osaka kyoiku University repository, 58(1), 261-278. 


\section{Copyright Disclaimer}

Copyright for this article is retained by the author(s), with first publication rights granted to the journal.

This is an open-access article distributed under the terms and conditions of the Creative Commons Attribution license (http://creativecommons.org/licenses/by/3.0/). 